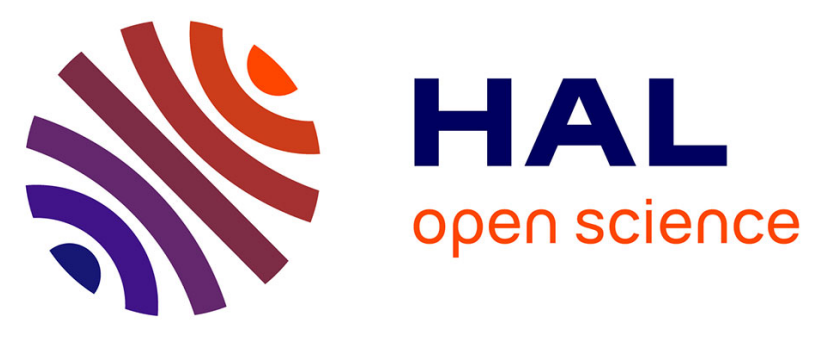

\title{
Shrouded Tidal Stream Turbine Simulation Model Development and Experimental Validation
}

Jorel Flambard, Yassine Amirat, Mohamed Benbouzid, Gilles Feld, Nicolas Ruiz

\section{- To cite this version:}

Jorel Flambard, Yassine Amirat, Mohamed Benbouzid, Gilles Feld, Nicolas Ruiz. Shrouded Tidal Stream Turbine Simulation Model Development and Experimental Validation. IECON 2020 - 46th Annual Conference of the IEEE Industrial Electronics Society, Oct 2020, Singapore, Singapore. pp.28252831, 10.1109/IECON43393.2020.9255270 . hal-03363056

\section{HAL Id: hal-03363056 https://hal.science/hal-03363056}

Submitted on 4 Nov 2021

HAL is a multi-disciplinary open access archive for the deposit and dissemination of scientific research documents, whether they are published or not. The documents may come from teaching and research institutions in France or abroad, or from public or private research centers.
L'archive ouverte pluridisciplinaire HAL, est destinée au dépôt et à la diffusion de documents scientifiques de niveau recherche, publiés ou non, émanant des établissements d'enseignement et de recherche français ou étrangers, des laboratoires publics ou privés.

\section{(c)(1)}

Distributed under a Creative Commons Attribution| 4.0 International License 


\title{
Shrouded Tidal Stream Turbine Simulation Model Development and Experimental Validation
}

\author{
Jorel Flambard ${ }^{* \dagger}$, Yassine Amirat *, Mohamed Benbouzid ${ }^{\dagger \S}$, Gilles Feld ${ }^{*}$ and Nicolas Ruiz ${ }^{\ddagger}$ \\ *Institut de Recherche Dupuy de Lôme (UMR CNRS 6027 IRDL) \\ ISEN Yncréa Ouest Brest, 29200 Brest, France; \\ Email: jorel.flambard@isen-ouest.yncrea.fr; yassine.amirat@isen-ouest.yncrea.fr; gilles.feld@isen-ouest.yncrea.fr \\ ${ }^{\dagger}$ Institut de Recherche Dupuy de Lôme (UMR CNRS 6027 IRDL) \\ University of Brest, 29238 Brest, France; \\ Email: mohamed.benbouzid@univ-brest.fr \\ ‡GUINARD Energies, 29200 Brest, France; \\ Email: n.ruiz@guinard-energies.com \\ $\S$ College of Logistics Engineering \\ Shanghai Maritime University, Shanghai 201306, China
}

\begin{abstract}
This paper presents the modeling steps of a shrouded tidal stream turbine. The main goal of this modeling is to allow the behavior simulation of the converter in order to anticipate its operation under specific conditions and its later development. The observation time scale of the operation system may extend from tidal period (several hours) to converter switching period (milliseconds to microseconds). An assessment of different modeling methodology, based on instantaneous and average models, is carried out. Instantaneous modeling offers the possibility to observe system electrical dynamics, which are driven by power switches, at the expense of an important computational time. In that respect, an average modeling is considered for greater period-scale analyses. So as to reduce the computational time induced by the power electronic modeling, cosimulations between Simulink and PSIM are also established. Simulation results are furthermore compared with some experimental data of an industrial shrouded tidal stream turbine prototype immersed and tested in real off-grid condition. The results and differences observed are sufficiently relevant to consider these models as references for further development.

Index Terms-shrouded tidal stream turbine, hydrokinetic turbine, power converter, modeling, Matlab/Simulink, PSIM
\end{abstract}

\section{INTRODUCTION}

Stream current power (SCP), provided by the hydrokinetic energy conversion to electricity, is a renewable energy source which has the advantage of being predictable on a longer time scale than the wind energy or the photovoltaic in tidal case, and to be continuous in case of river exploitation. The energy source choice however is not absolute, and as mentioned in [1], the complementary use of these types of renewable sources, when available, should be considered in (isolated) microgrids. The academic and industrial consideration about SCP sector has been studied in [2], with the highlight of a primary interest on the mechanical converter study and the location energy potential estimation. In that respect, this paper focus on the electromechanical part with the proposal of a shrouded tidal stream turbine (STST) modeling procedure, which can be adapted more specifically to an industrial electrical integration.
This paper is organized as follows: Section II first presents and explains the methodology followed to model a hydrokinetic power converter recently developed. The proposed models are then simulated and compared with experimental data in Section III. Finally, Section IV summarizes and discusses the results and observations presented in this paper.

\section{MODELING METHODOLOGY}

The STST is based first of all on the choice of the generator and its converter, according to the advantages and disadvantages considered [3]. The following models are based on a power converter architecture featured by GUINARD Energies company for the river or tidal hydrokinetic turbine Poseide 154, Fig. 1. The architecture synoptic is given in Fig. 2. The operation of the tidal turbine has been primarily considered, the modeling of the PV converter and the DC/AC part are not discussed in this paper.

\section{A. Matlab/Simulink Instantaneous Modeling (MSIM)}

In Simulink, the power part of the conversion chain is modeled using the Simscape library. The modeling is detailed in Fig. 3 as follows:

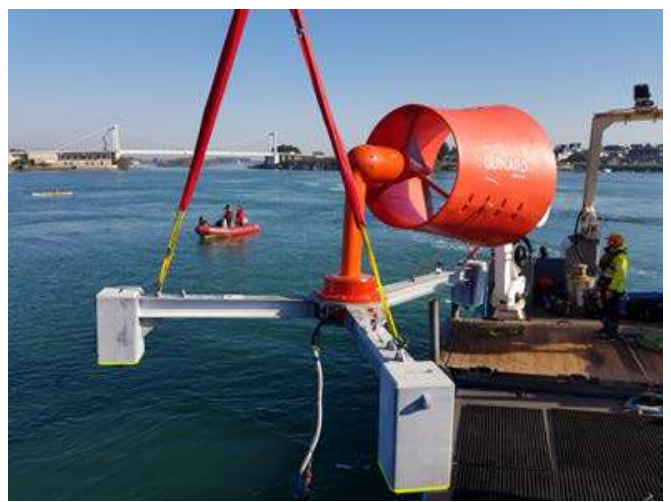

Fig. 1. Shrouded tidal stream turbine Poseide P154. (C) Guinard Energies. 


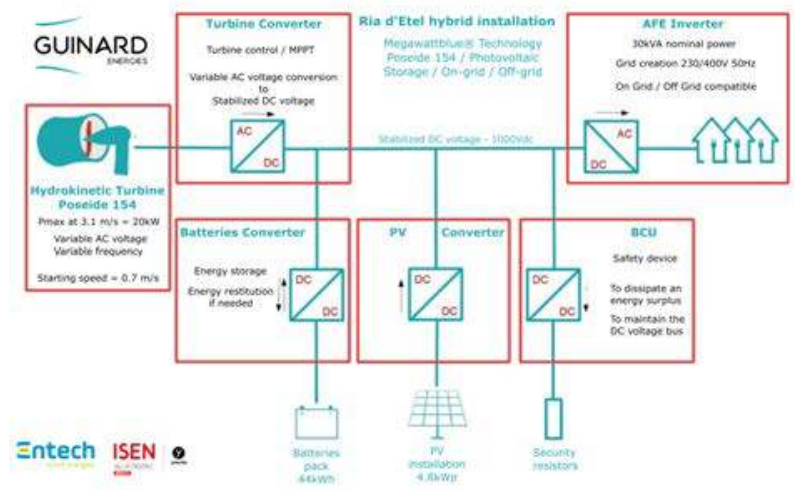

Fig. 2. Architecture synoptic of a Poseide P154 installation. (C) Guinard Energies.

1) Tidal stream turbine. Input variables: water velocity $V_{\text {cur }}$, mechanical rotation speed $\Omega_{\text {mech }}$; Output variables: Turbine torque $C_{t u r b}$, mechanical power $P_{\text {mech }}$. The extractable mechanical power for a given current speed $V_{\text {cur }}$ is detailed by (1)-(2):

$$
\begin{gathered}
P_{\text {mech }}=1 / 2 . \rho . C_{p}(\lambda) \cdot S \cdot V_{\text {cur }}{ }^{3} \\
\lambda=\omega \cdot R_{a} / V_{\text {cur }}
\end{gathered}
$$

With $\rho$ the density of water $\left(\mathrm{kg} / \mathrm{m}^{3}\right), C_{p}(\lambda)$ the power coefficient of the turbine reflecting the power extraction efficiency as a function of the mechanical rotation speed $\Omega_{\text {mech }}(\mathrm{rad} / \mathrm{s})$, $R_{a}$ turbine radius (m), $S$ the section swept by the pales $\left(\mathrm{m}^{2}\right)$ and $V_{\text {cur }}$ the water velocity $(\mathrm{m} / \mathrm{s})$. From the $C_{p}(\lambda)$ curve previously defined and supplied by the manufacturer, the turbine power and generator torque are calculated. The $C_{p}$ curve used in this paper has a proprietary shape for nonpitchable two-blade turbine, but the interested reader can easily replace it with another one.

2) Generator. Block modeling the electric machine used (here a three-phase permanent magnet synchronous machine). Input variable: $C_{\text {turb }}$; Output variable: $\Omega_{\text {mech }}$; Simscape variables: machine phases $P h_{a b c} . \Omega_{m e c h}$ is only connected to the turbine, as the architecture in this case does not use a speed sensor. A speed estimator using the measurement of machine voltages to define an estimated rotation speed $\Omega_{e s t}$ is used. Subsequently, the system control uses this variable $\Omega_{e s t}$.

3) Cable. Modeling the electrical properties of the underwater cable. Its complexity will depend on its structure and the length considered. Particular attention must be paid to the analysis of transient overvoltages generated by power electronics and circuit breakers [4], [5]. The pi model can be used in case of short distance between the generator and its converter, and low frequency operation. In the presented case, only the resistive property has been taken into account.

4) Safety/control devices. This block allows to manage specific system operation cases (braking, regulation start/stop, characteristic fault,...). Input variable: $\Omega_{e s t}$; Output variables:
Command signals 'COM_DC', 'KM_A', 'close'; Simscape variables: $P h_{a b c}$.

5) Turbine converter. Provides the tidal turbine control and the interface between the generator and the common DC bus of the architecture. Input variables: Control signals for power switches 'COM_Turbine' and 'COM_DC' ; Output variable: Electrical power $P_{e}$ calculated from voltage and current measurements on the DC side.

6) Battery converter. Models a battery with a DC/DC converter (in this case interleaved with 3 branches) providing voltage regulation of the common DC bus [6]. Input variables: Control signals of the converter power switches; Output variables: currents circulating in the branches and battery current.

7) Dump Load converter. DC/DC converter with resistive loads activated in case of consumption/generation unbalance which causes a critical rise in the DC bus voltage. Input variables: Voltage measurement of the common DC bus $U_{d c}$, Control signal ' $B C U$ ' of the power switches. The converter behavior can also be modeled by a current source controlled as a function of the $U_{d c}$ voltage.

8) Equivalent DC user load. Replacing the inverter stage with its control, this block makes it possible to simulate user consumption profiles from a controlled current source. Input variables: Power consumption profile $P_{u s e r}$ and $U_{d c}$.

To this power chain is also associated a control chain:

- Turbine speed estimator block. Different control schemes without mechanical speed/position sensor have been presented in [7]. These schemes, applied for variable speed wind energy conversion systems, can fully be transferred to the STST. From the measurement of the phase voltages of the generator, the zero-crossing detection of the voltages and the measurement of the time between these crossings make it possible to calculate the electrical frequency and thus the generator speed rotation.

- Turbine converter controller. Different control strategies can be used [8], [9], [10]: speed regulation, power regulation and Maximum Power Point Tracking with Perturb \& observe (MPPT P\&O). Input variables: $\Omega_{e s t}$, Command signals 'COM_DC', ' $K M_{-} A$ ', speed setpoint $N_{\text {cons }}$, $P_{e}$ and regulation update frequency $F_{\text {ech }}$; Output variable: Command signal 'COM_Turbine'.

- Battery converter controller. Elaborating the control signals for the battery DC/DC converter. Input variables: $U_{d c}$, voltage setpoint $U_{d c_{-} c o n s}$, branch current measurements ; Output variables: Control signals of the battery converter power switches.

This first choice of modeling, theoretically ideal for its fidelity in modeling an architecture, naturally implies a significant calculation cost. Moreover, the lack of knowledge of the real integration characteristics of the architecture (measurements filtering e.g.), often considered as an industrial know-how, limits the possibilities of complete modeling.

\section{B. Simulink/PSIM Instantaneous Modeling}

The impact of power electronics and associated switching dynamics has been highlighted from the first modeling method 


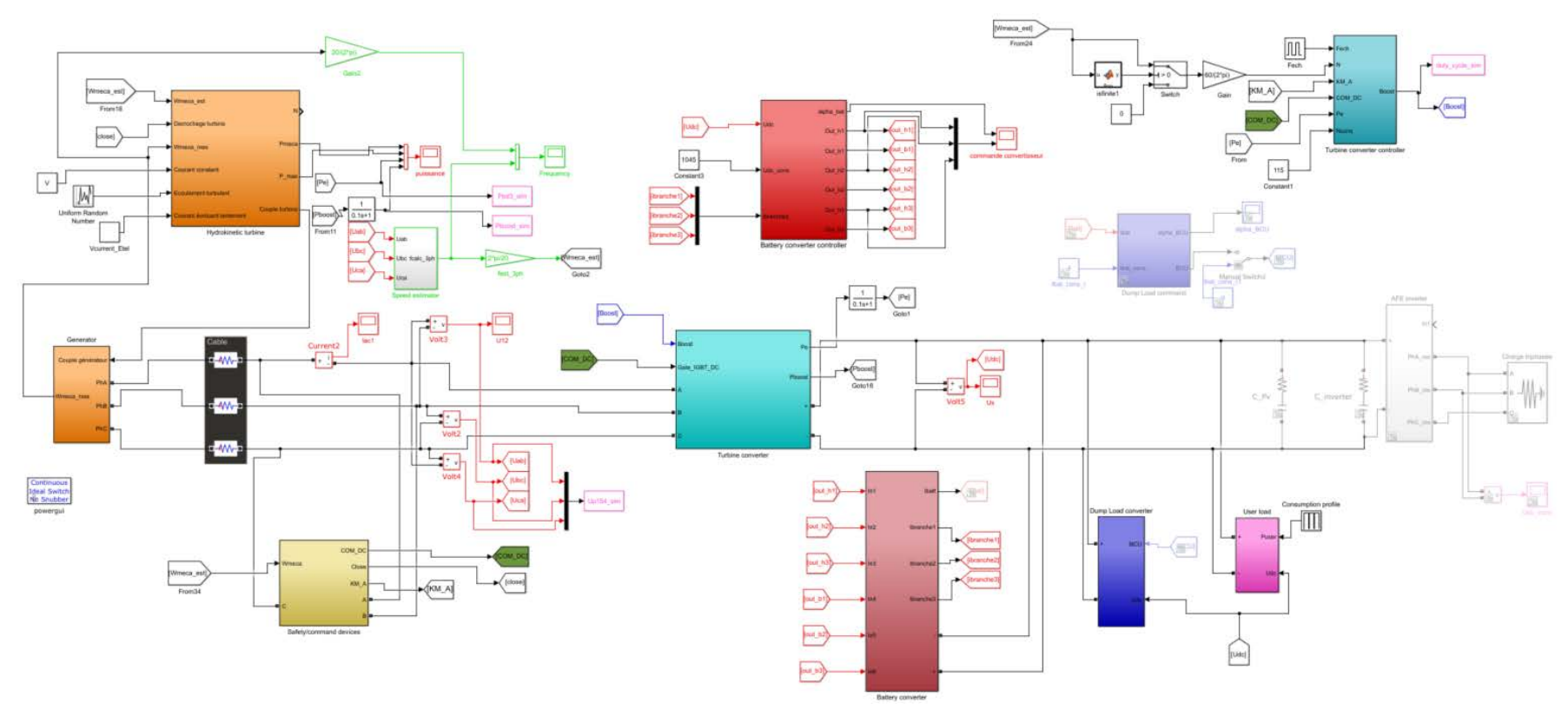

Fig. 3. Tidal stream turbine converter modeling with Simulink.

exclusively in Simulink. Thus, the use of the PSIM software, whose solver is more dedicated to power electronics simulation, was chosen to simulate this part of the architecture. Both the control part and the turbine remain modeled in Simulink, Fig. 4. Due to the incompatibility of interfacing Simscape signals with PSIM connections, the generator is also modeled in PSIM. The machine blocks in PSIM do not allow direct observation of the developed electromagnetic torque, so the machine used has been remodeled from (3)-(6):

$$
\begin{gathered}
v_{k}=R \cdot i_{k}+L \cdot d i_{k} / d t+e_{k} \\
e_{k}=\Omega_{m e c h} \cdot K_{\phi} \cdot \sin [p \Theta-2 \pi / 3 .(k-1)] \\
J . d \Omega_{m e c h} / d t=T_{e m}-T_{\text {turb }}-f . \Omega_{m e c h} \\
T_{e m}=\sum_{k} i_{k} \cdot K_{\phi} \cdot \sin [p \Theta-2 \pi / 3 .(k-1)]
\end{gathered}
$$

With $v_{k}$ the phase-to-neutral stator voltage $(\mathrm{V}), R$ the stator resistance $(\Omega), i_{k}$ the stator current (A), $L$ the cyclic inductance $(\mathrm{H}), e_{k}$ the back emf $(\mathrm{V}), K_{\phi}$ the flux constant of permanent magnets (V/rad.s), $p$ the number of pole pairs, $\Theta$ the mechanical rotor angle $(\mathrm{rad}), J$ the inertia moment applied to the rotor $\left(\mathrm{kg} \cdot \mathrm{m}^{2}\right), T_{e m}$ and $T_{\text {turb }}$ respectively the electromagnetic and turbine torque (N.m), $f$ the viscous friction coefficient (N.m/rad.s) and $k=1,2,3$ the phase number.

Simulink/PSIM cosimulations is based on the SimCoupler module that interfaces between the two software applications. In Simulink, the "architecture_simulink_v3" block centralizes the signals sent to PSIM (left side) and those received (right side).
This second modeling choice allows an effective reduction of the computation time compared to the first method, while allowing most of the electrical dynamics to be observed. It remains however time-consuming to simulate a tidal cycle.

\section{Simulink Average Modeling (SAM)}

The average evolution of the quantities with respect to the switching times allows a simplified modeling of the converters, based on the links between the current/voltage variables at the input/output of the elements, in Simulink. Variable speed operation (i.e. variable power injection level) may involve operation of the converters in continuous and/or discontinuous conduction mode [11], [12]. The control part is identical to that of the previous models. Depending on the characteristics of the electric machine used, an average model of the electric machine with its converter can be made [13] or obtained after having characterized its behavior over a nominal speed range of the SCP system.

\section{MODEL ANALYSES WITH EXPERIMENTAL MEASUREMENTS}

These models were tested through simulations and evaluated with each other and with experimental data from a test campaign. The parameters used in simulation are, as far as possible, directly derived from the actual characteristics of the conversion architecture, or assumed in case of unawareness. In the case of average modeling, particular attention was paid to identifying the parameters of the machine-converter equivalent model.

\section{A. Experimental Data Features}

The experimental data come from an installation in the Etel's ria, France, which took place at the beginning of 2019. 


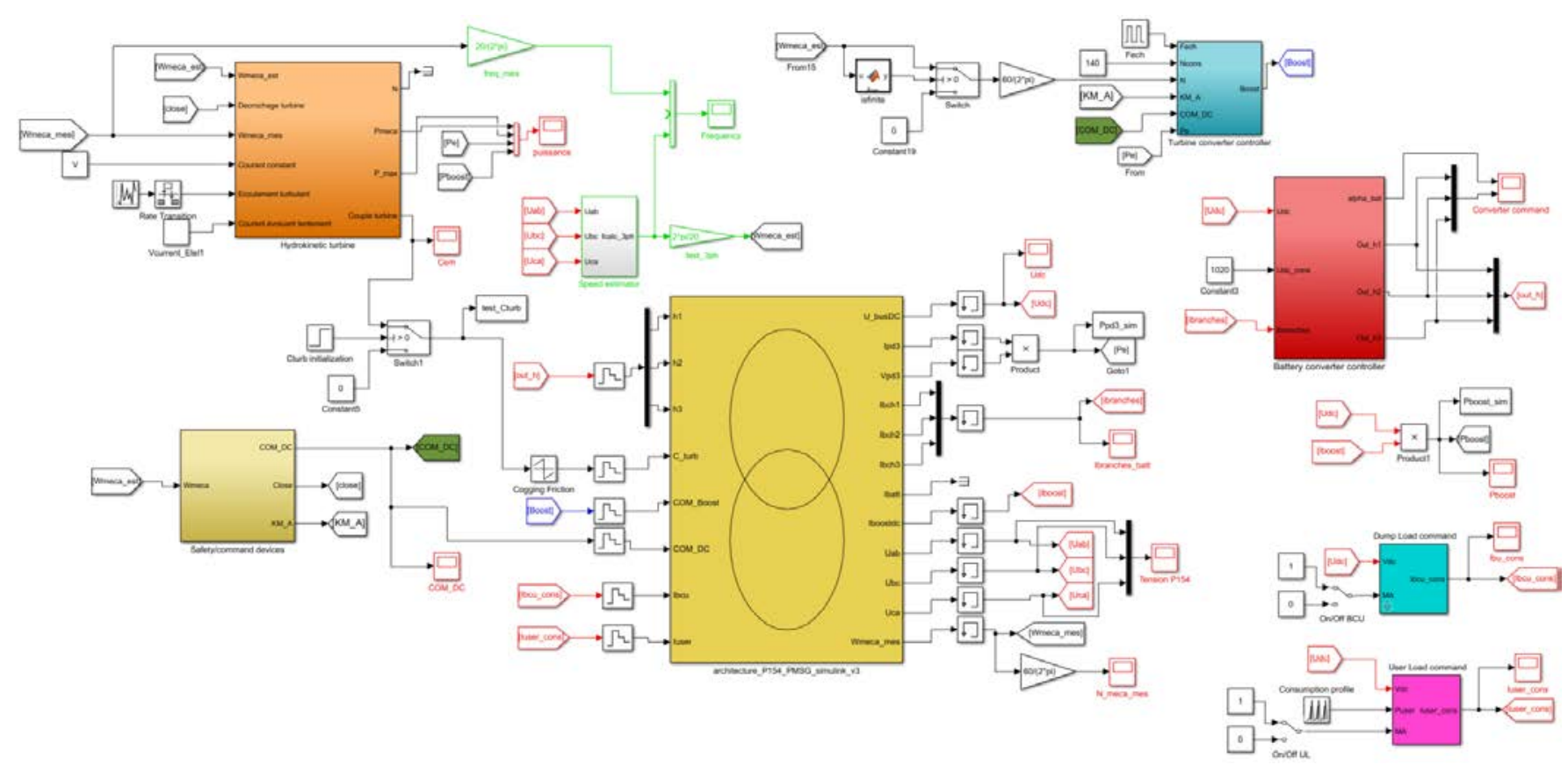

Fig. 4. Tidal stream turbine converter modeling with cosimulation.

It served as an operational demonstrator, validating the proposed hybrid electric conversion chain and the entire secondgeneration tidal turbine technology: current acceleration at the rotor by means of an accelerator duct, and free orientation of the tidal turbine in the axis of the current. The test period took place initially in off-grid configuration and then in ongrid configuration on the French electricity grid. Since the immersion site is in an estuarine environment, the electrical production of the system is influenced by tidal cycles Fig. 5. $V_{\text {cur }}$ is thus higher at ebb tides where the tidal influence is additive to the normal flow of the river. Subsequently, three distinct ebb tide periods were considered:

- Tidal Coefficient 55, 03/03/19.

- Tidal Coefficient 114, 21/03/19.

- Tidal Coefficient 101, 21/04/19.

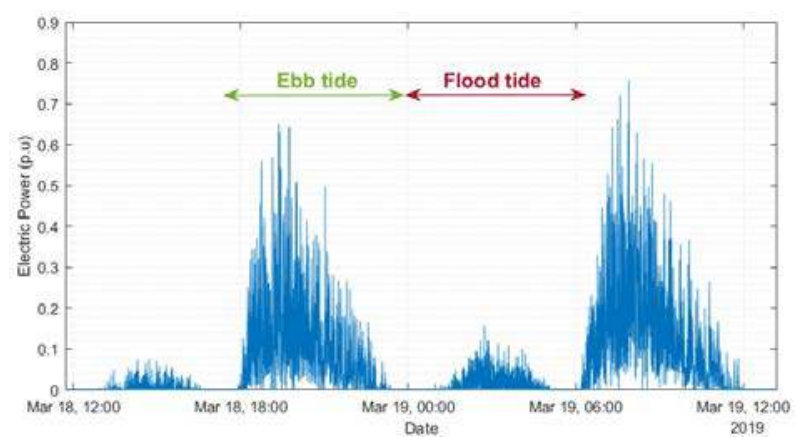

Fig. 5. Evolution of the electricity production over one day.

\section{B. Study Framework}

A water velocity profile $V_{\text {cur }}$ from each tide is used as input to the simulations. It was recorded during the actual system operation in Etel's ria. Table I. regroups variables of interest used in the simulation. These variables, with the exception of $\Omega_{m e c h}$, are experimentally available. However, under constraints of storage memory and transmission rate, the acquisition of these data could only be carried out at $1 \mathrm{~Hz}$, thus preventing the observation of any experimental electrical dynamics. On this point, model dynamics can only be compared with each other. Finally, taking into account the cost of calculating the simulations, each tide was simulated over a $T_{\text {sim }}$ time of $30 \mathrm{~s}$, with linear interpolation applied between each measurement point used, as illustrated in Fig. 6.

\section{Results}

In order not to overload this paper, the results shown are for the period of operation at tidal coefficient 55 .

Fig. 7 shows the evolution of the mechanical rotational speed during a start of electrical production. The dash-dot

TABLE I

OBSERVED VARIABLES

\begin{tabular}{|c|c|c|}
\hline \multicolumn{3}{|c|}{ Description of variables } \\
\hline Full name & Variable name & Nature \\
\hline Estimated rotation speed & $\Omega_{e s t}$ & Estimated \\
\hline Mechanical rotation speed & $\Omega_{\text {mech }}$ & $/$ \\
\hline Turbine converter duty cycle & $\alpha_{\text {turb_conv }}$ & Calculated \\
\hline Turbine converter output power & $P_{\text {turb_conv }}$ & Computed \\
\hline Electrical machine output power & $P_{\text {elec }}$ & Computed \\
\hline
\end{tabular}




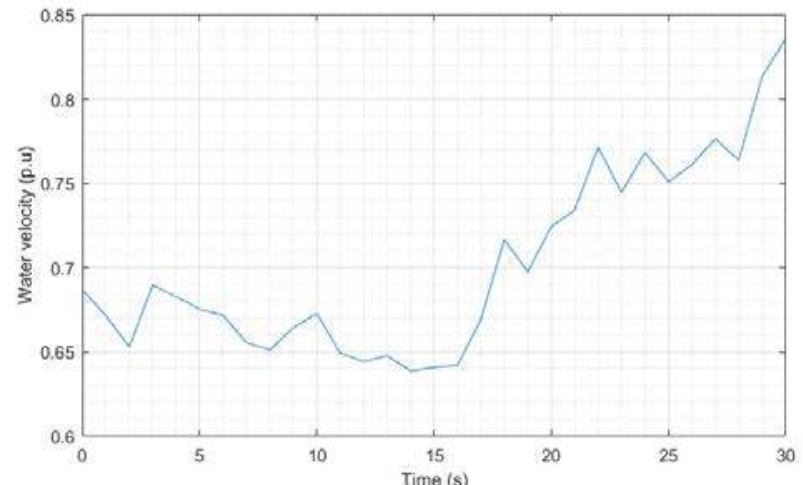

Fig. 6. Water speed profile $V_{\text {cur }}$ used as input, tidal coeff 55 .

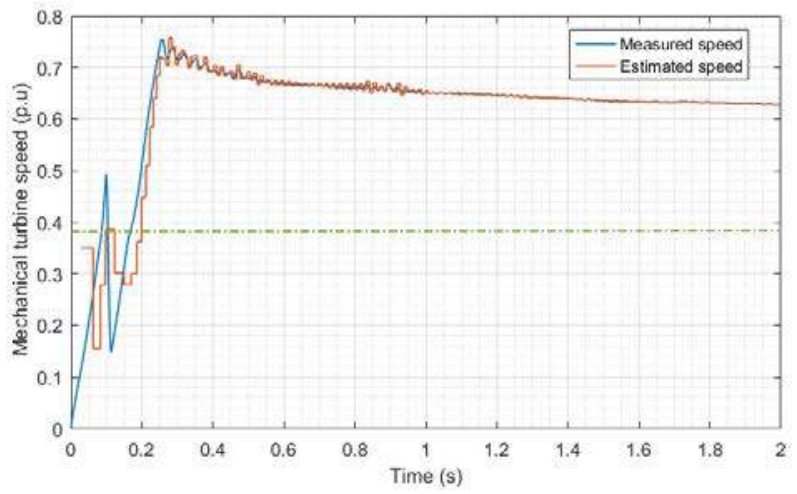

Fig. 7. Evolution of measured and estimated mechanical speed during a start.

green line indicates the threshold value for the start of regulation, i.e. for connecting the alternator to the entire conversion chain. The starting moment can be identified by the sudden drop in turbine speed. It should be noted that low-speed estimation delays and small estimation errors (on average below 5\%) are not critical in the regulation of SCP generation. Thus, on the condition of a good initialization of the regulation with respect to the electrical and mechanical dynamics of the whole conversion chain, the normal operation of the system is observable on the figure, with a progressive decrease of the rotation speed induced by a decrease of the river current speed, Fig. 6.

Fig. 8 shows the evolution of the extracted powers and the estimated turbine rotation speed observed during the submersion period. The observation period from 08:23:30 to $08: 24$ corresponds to the $T_{\text {sim }}$ simulation period with the $V_{\text {cur }}$ profile. The rapid evolution of $\Omega_{\text {est }}$ (i.e $V_{\text {cur }}$ ) over this period of time is notably due to the turbulent hydrodynamics of the location. The tidal turbine production is operational as shown by the evolution of $P_{\text {turb_conv }}$. It follows that of $V_{\text {cur }}$, although it has its own dynamics influenced by the regulation of the turbine converter and by the voltage fluctuations of the common DC bus. $\alpha_{\text {turb_conv }}$ shows a progressive decrease implying, given the increase in $V_{c u r}$, an increase in the power extracted by the tidal turbine.

Fig. 9-10 show the evolutions of the variables during

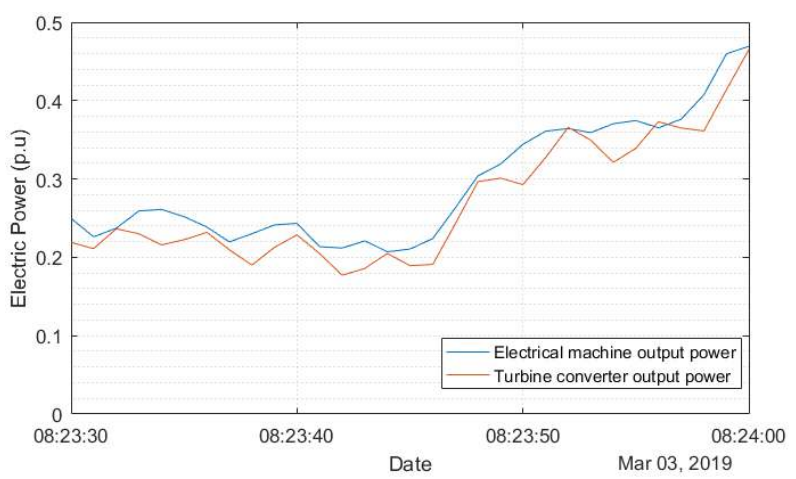

(a)

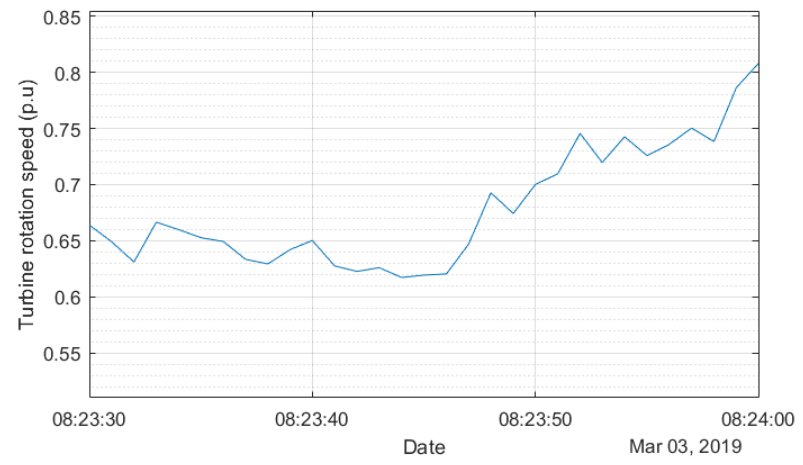

(b)

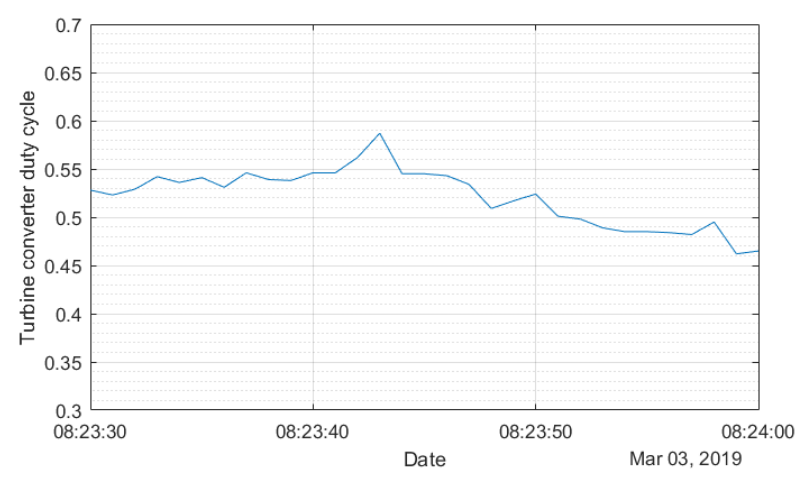

(c)

Fig. 8. Evolution of experimental variables during the ebb tide with tidal coefficient 55. (a) $P_{\text {elec }}, P_{\text {turb_conv }}$, (b) $\Omega_{\text {est }}$, (c) $\alpha_{\text {turb_conv }}$.

simulations in the respective cases of MSIM and SAM.

The significant voltage and current fluctuations at the beginning of the simulations are due to the initial conditions of the system (capacity preload, initial conditions of the converters, etc.). In all cases, the changes in the variables are consistent with those observed experimentally. The oscillations not observable with the experimental data but visible in simulation on power, rotational speed and voltages, Fig. 9 are due to the setting of the turbine converter control parameters and the updating of the rotational speed estimate. This latter is a sensitive variable for changing the operating point of the system. The simplifications made in the average modeling 


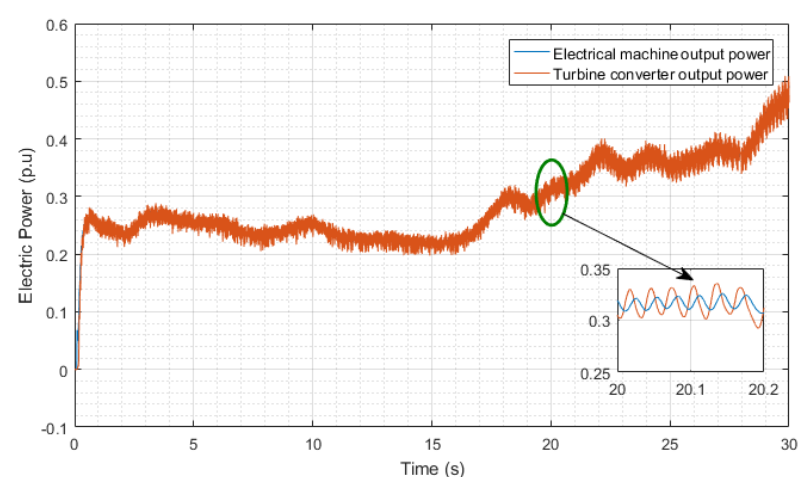

(a)

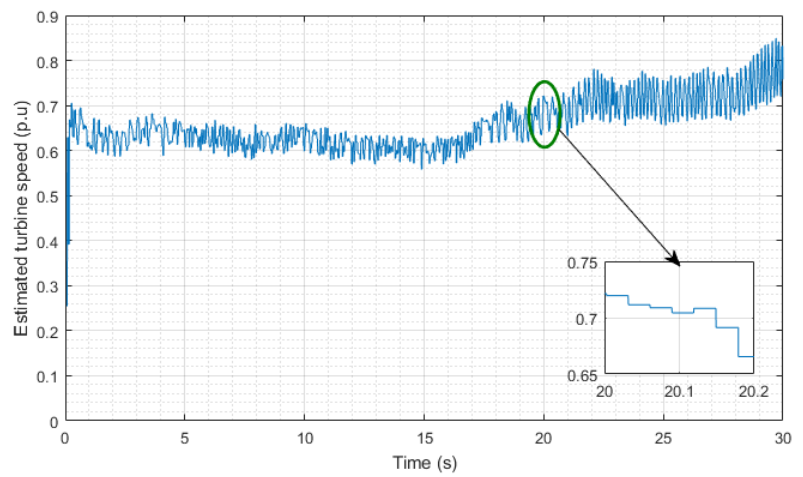

(b)

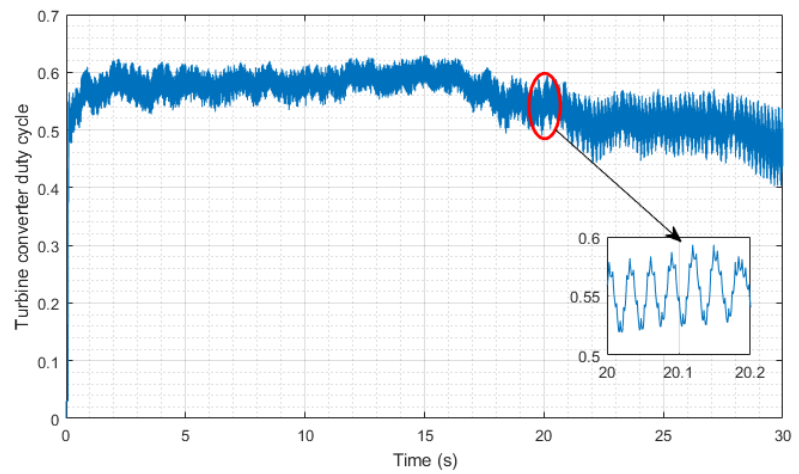

(c)

Fig. 9. Evolution of variables, Matlab/Simulink Instantaneous Modeling. (a) $P_{\text {elec }}, P_{\text {turb_conv }}$, (b) $\Omega_{\text {est }}$, (c) $\alpha_{\text {turb_conv }}$.

result in a higher power extraction, thus a higher rotational speed and a lower duty cycle, Fig. 10.

\section{DISCUSSION AND CONCLUSION}

Table II presents a comparison of the simulation computation time on the same platform, with an ode3 fixed-step solver. SAM is, unsurprisingly, the fastest, and the use of PSIM for power electronics simulation results in a significant reduction in computing time. The quantitative comparison of SAM with MSIM for this Vcurrent profile shows a median deviation of $12.2 \%$ for power, $2.3 \%$ for $\Omega_{e s t}$ and $3.3 \%$ for $\alpha_{t u r b}$ conv .

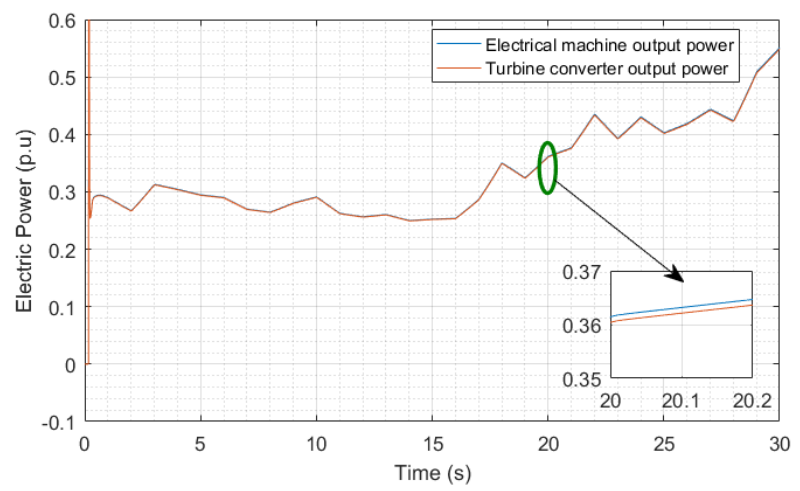

(a)

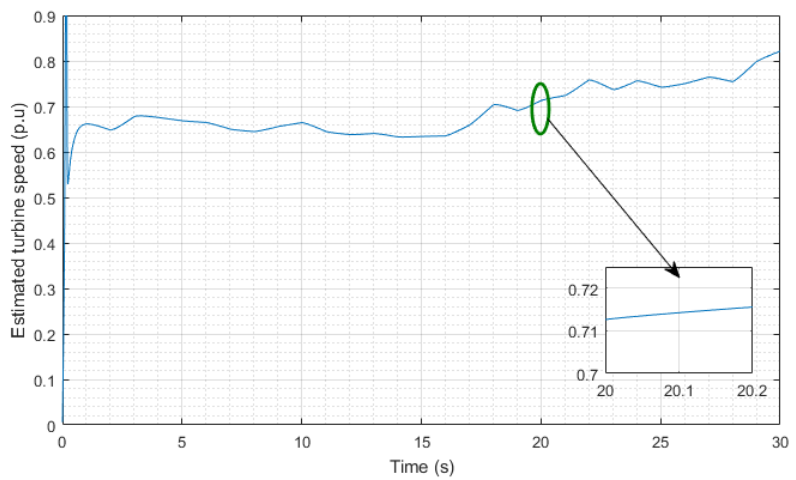

(b)

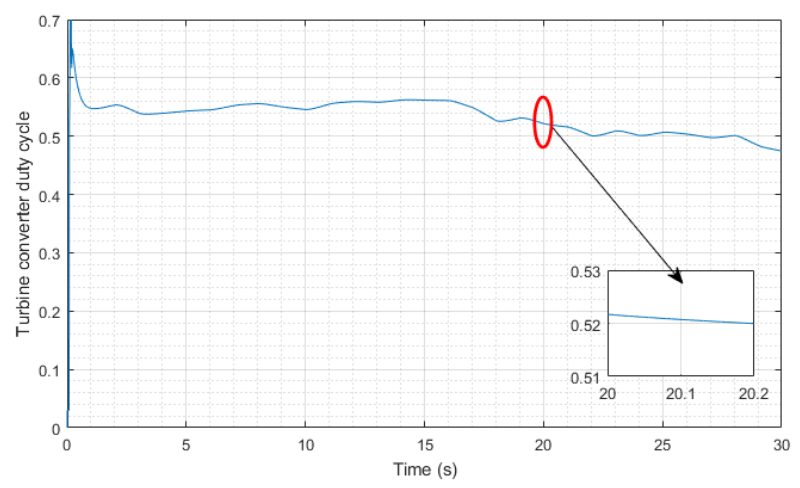

(c)

Fig. 10. Evolution of variables, Simulink Average Modeling. (a) $P_{\text {elec }}$, $P_{\text {turb_conv }}$, (b) $\Omega_{\text {est }}$, (c) $\alpha_{t u r b \_c o n v}$.

Comparison with the experimental data shows a difference of $13.6 \%$ for power, $1.9 \%$ for $\Omega_{\text {est }}$ and $0.9 \%$ for $\alpha_{\text {turb_conv }}$.

The fidelity and possibility of operation analysis with instan-

TABLE II

COMPUTATION TIME COMPARISON

\begin{tabular}{|c|c|c|}
\hline Type of simulation & Time Step & Time \\
\hline Matlab/Simulink Instantaneous Modeling & $10 \mu \mathrm{s}$ & $7875 \mathrm{~s}$ \\
\hline Simulink/PSIM Instantaneous Modeling & $10 \mu \mathrm{s}$ & $1702 \mathrm{~s}$ \\
\hline Simulink Average Modeling & $10 \mu \mathrm{s}$ & $153 \mathrm{~s}$ \\
\hline
\end{tabular}


taneous modeling, and the compromise between calculation cost/precision of the average modeling allows to validate the use of these models. The simulation of a tidal cycle is thus facilitated with SAM. These models can be used for the optimization of the controller, in the study of multi-hydrokinetic turbine architectures, and of faults in the HPC. The study of power transfers between the stabilized DC bus and the end users or an electrical grid (OFF/ON Grid configuration) will imply the consideration of the inverter and its associated control [14], depending on the operating location of the HPC.

Thus, a shrouded tidal stream turbine modeling procedure for modeling an electrical architecture towards an industrial context has been proposed in this paper. Following the example of the wind development, the sustainability of the SCP sector implies thorough studies of the system electrical dynamics particularly since there is not yet any harmonization of the architectures used or proposed by the industrialists. A good anticipation of the turbine/generator/converter electromechanical performances remains essential to ensure the greatest service continuity of the STST.

\section{ACKNOWLEDGMENT}

This work is supported by GUINARD Energies (Brest) under the ANRT CIFRE Program (France).

\section{REFERENCES}

[1] P. B. L. Neto, O. R. Saavedra, and D. Q. Oliveira, "The effect of complementarity between solar, wind and tidal energy in isolated hybrid microgrids," in Renewable Energy, vol. 147, part 1, 2020, pp. 339-355.

[2] J. Flambard, Y. Amirat, G. Feld, M. Benbouzid, and N. Ruiz, "River and Estuary Current Power Overview," in Journal of Marine Science and Engineering, vol. 7, no. 10, p. 365, Oct. 2019.

[3] H. Chen, T. Tang, N. Aït-Ahmed, M.E.H. Benbouzid, M. Machmoum and M.E.H. Zaïm, "Attraction, challenge and current status of marine current energy," in IEEE Access, vol. 6, pp. 12665-12685, 2018.

[4] M. Kuschke and K. Strunz, "Transient Cable Overvoltage Calculation and Filter Design: Application to Onshore Converter Station for Hydrokinetic Energy Harvesting," in IEEE Transactions on Power Delivery, vol. 28, no. 3, pp. 1322-1329, July 2013.
[5] B. Liu, W. H. Tang, X. D. Chen and Q. H. Wu, "Modeling of transient overvoltages in wind power plants," 2014 IEEE PES Asia-Pacific Power and Energy Engineering Conference (APPEEC), Hong Kong, 2014, pp. $1-6$

[6] Y. Amirat, G. Feld, E. Elbouchikhi, M. Benbouzid, H. Kermarrec, N. Ruiz and C. Leloup, "Design and applications of a tidal turbine emulator based on a PMSG for remote load," IECON 2017 - 43rd Annual Conference of the IEEE Industrial Electronics Society, Beijing, 2017, pp. 2437-2441, doi: 10.1109/IECON.2017.8216410.

[7] Y. Zhao, C. Wei, Z. Zhang and W. Qiao, "A Review on Position/Speed Sensorless Control for Permanent-Magnet Synchronous Machine-Based Wind Energy Conversion Systems," in IEEE Journal of Emerging and Selected Topics in Power Electronics, vol. 1, no. 4, pp. 203-216, Dec. 2013.

[8] Soedibyo, M. Ridwan, A. Pradipta, S. Anam and M. Ashari, "Comparison of $\mathrm{P} \& \mathrm{O}$ and inceremental conductance based maximum power point tracking for wind turbine application in remote area (Case study: Gili genting Island, Madura, East Java, Indonesia)," 2018 IEEE International Conference on Innovative Research and Development (ICIRD), Bangkok, 2018, pp. 1-6.

[9] M. Michas, C. E. Ugalde-Loo, W. Ming, N. Jenkins and S. Runge, "Maximum power extraction from a hydrokinetic energy conversion system," in IET Renewable Power Generation, vol. 13, no. 9, pp. 14111419, 872019 .

[10] K. Musasa, M. N. Gitau and R. C. Bansal, "Dynamic analysis of DC-DC converter internal to an offshore wind farm," in IET Renewable Power Generation, vol. 9, no. 6, pp. 542-548, Aug. 2015.

[11] M. Rahimi, "Modeling, control and stability analysis of grid connected PMSG based wind turbine assisted with diode rectifier and boost converter," International Journal of Electrical Power \& Energy Systems, Vol. 93, 2017, pp. 84-96.

[12] D. Suski and D. A. Górski, "Modeling and Simulation of the Averaged Dynamics of PWM Converters Operating in CCM and DCM," 2018 23rd International Conference on Methods \& Models in Automation \& Robotics (MMAR), Miedzyzdroje, 2018, pp. 849-854.

[13] L. Xu, G. Wang, L. Fu, Y. Wu and Q. Shi, "General average model of D-PMSG and its application with virtual inertia control," 2015 IEEE International Conference on Mechatronics and Automation (ICMA), Beijing, 2015, pp. 802-807.

[14] R. C. A. Palacio, M. Mezaroba and J. R. Pinheiro, "VSG based control application for inverter-interfaced distributed generators in microgrids," 2017 Brazilian Power Electronics Conference (COBEP), Juiz de Fora, 2017, pp. 1-6. 